\title{
Simulation Of Natural Gas Combustion Process Using Pressure Based Solver
}

\author{
Osama H. Ghazal, Associate Prof. \\ Mechanical and Industrial Engineering Department, \\ Applied Sciences Private University, Amman—Jordan
}

doi: 10.19044/esj.2016.v12n12p81 URL:http://dx.doi.org/10.19044/esj.2016.v12n12p81

\begin{abstract}
The aim of this research is to simulate the combustion process for methane using different heat transfer models combined with various fuel injection techniques to better understand the combustion process and heat transfer process inside IC engine which reflect on the engine efficiency. The simulation has been carried out using Lotus Engineering software. This model solves the nonlinear momentum and continuity equations to satisfy the conservation of mass and the conservation of momentum laws. In this analysis a single cylinder four stroke SI engine has been simulated. The fuel used in the simulation is methane. Two fuel systems have been investigated port injection and direct injection. The Wiebe heat release curve has been used. Two widely used for SI engines heat transfer models presented in the simulation, Annand and Woschni. The intension in this paper is to study the effect of various fuel systems and heat transfer models on engine efficiency for different engine speeds. Moreover, the evaluation of the heat transfer models for natural gas SI engine will be tested. Brake power, mean effective pressure, specific fuel consumption, brake thermal efficiency, and heat transfer rate were calculated and discussed to show the effect of varying heat transfer models and fuel systems on engine efficiency.
\end{abstract}

Keywords: SI engines, alternative fuel, heat transfer, engine modeling, fuel systems

\section{Introduction}

The overall performance of IC engine is the result of various interactions processes inside the engine. These processes are very complicated and not fully investigated. The heat transfer inside the engine is one of the most complicated processes due to the rapid change pressure and temperature inside the engine. The first model for engine heat transfer has been presented by Nusselt (Nusselt, 1923) assuming a steady heat flux which 
can be obtained by averaging the surface temperature with time. The modified correlation of Nusselt's formula was presented by Brilling (Brilling, 1958) and Van Tyens (Van Tyens, 1962) who changed the mean engine speed correlation. The first experiment to measure the instantaneous heat flux has been done by Eichelberg and modified by Pflaum (Pflaum, 1961). This model is suitable for low speed engine. Two widely used heat transfer models for SI engines are Annaned (Annaned, 1963) and Woschni (Woschni, 1967). Both models are based on steady turbulent convection heat transfer. Zero-dimensional models assumed the same heat transfer coefficients for all the heat transfer surfaces in the cylinder. Multi-dimensional modeling offers the ability to model the gas side fluid mechanics and combustion (Borman, 1987). The lack of full measurements engine parameters and detailed data concerning combustion process and heat transfer phenomena are the major problems to carry out engine experiment (Borman, 1987). The control of engine emissions and reduction of fuel consumption have added new challenges that automobile companies have to satisfy. Many solutions have been proposed by researchers to reduce engine pollution and increase performance one of them is to use an alternative fuel for both gasoline and diesel engine (Karim, 1996). Many studies have presented the performance of SI engines with blend hydrogen - gasoline fuel (Hoehn \& Baisly, 1975; Sher \& Hacohen, 1989; Hacohen \& Sher, 1989) and hydrogen - natural gas fuel (Ghazal, 2013; Raman \& Hansel \& Fulton 1996; Nagalingam \& Duebel, 1983; Das, 1996; Annand \& Balamurugan, 2005). To gain the maximum benefits from the alternative fuel combustion a suitable heat transfer model should be used. Many researchers had investigated the effect of different heat transfer models on SI engine operating with alternative fuels. Demuynck (Demuynck, 2011) had studied the applicability of Annand and Woschni heat transfer models for hydrogen fuel operating with SI engine conditions. They evaluated both models theoretically and experimentally. They concluded that the presented models are not suitable for using with hydrogen fuel because of the lack of some parameters that affect heat transfer in hydrogen engines but are suitable for fossil fuel with appropriate calibrations (Demuynck, 2011). Lounici (Lounici, 2011) have investigated various heat transfer models for natural gas engines using two-zone model approach. The Hohenberg, Woschni, Sitkei, Annand, and Eichelberg models have been presented and compared. They concluded that Hohenberg model is the more accuracy model for the simulation natural gas heat transfer process. Moreover, the Eichelberg equation is also an acceptable one (Lounici, 2011).

In this paper, to avoid the costly engine prototype a simulation model has been built and investigated. Recently, the professional simulation tools provides very important detailed information about the processes occur inside the engine than it is possible to obtain experimentally saving time and 
cost. Using methane for SI engine as an extra and clean fuel, improve overall engine performance, fuel consumption, and pollutant production. It provides better conditions for soft run of the engine and can increase engine durability (Szwaja, 2009). The objective of this study is to find out the effect of the different fuel induction technique and different heat transfer models on SI engines performance fueled with methane. The results show that the use of Woschni heat transfer model for the SI engine with methane fuel is recommended for all engine speed because it has high brake power, high thermal efficiency and lower fuel consumption. It has a good agreement with heat transfer model for gasoline fuel.

\section{Simulation model}

For the purpose of analysis a single cylinder spark ignition engine model has been designed. Both fuel systems (port injection and direct injection) combined with Annand and Woschni heat transfer models have been tested. The combustion process employed a single zone combustion model (Ferguson \& Kirkpatrick, 2001; Baur, 2001; Stone, 1990). The heat release rate can be defined using Wiebe model. The Wiebe model defines the mass fraction burned as:

$$
m_{\text {frac }}=1.0-\exp ^{-A\left[\frac{\theta}{\theta_{b}}\right]^{M-1}}
$$

Two widely used heat transfer models, Annaned and Woschni are presented and compared $[16,6]$. Both models are based on steady turbulent convection heat transfer (Borman, 1987).

\section{Annand model}

This model based on Reynolds number which is based on the piston speed. Annand proposed that gas properties must be taken as the bulk mean temperature instead of the average temperature (Borman, 1987).

The connective heat transfer model proposed by Annand is defined as (Annand, 2005):

$$
\frac{h D_{c y l}}{k}=A \operatorname{Re}^{B}
$$

Where: $\mathrm{h}=$ heat transfer coefficient $\left[\mathrm{W} / \mathrm{m}^{2} \mathrm{~K}\right] ; \mathrm{A}=$ Annand open or closed cycle coefficient $=(0.2$ for port injection and 1.1 for direct injection $)$; $\mathrm{B}=$ Annand open or closed cycle coefficient $=(0.8$ for port injection and 0.7 for direct injection); $\mathrm{k}=$ thermal conductivity of gas in the cylinder [W/m.K]; Dcyl = cylinder bore; and Re = Reynolds number based upon mean piston speed and the engine bore (Ghazal, 2013). 
The heat transfer per unit area of cylinder wall is defined as:

$\frac{d Q}{A}=h\left(T_{\text {gas }}-T_{\text {wall }}\right)+C\left(T_{\text {gas }}^{4}-T_{\text {wall }}^{4}\right)$

Where: $\mathrm{C}=$ Annand coefficient.

\section{Woschni model}

Woschnie was used a heat balance to determine the total heat transferred to the combustion chamber walls for each process of engine cycle (Woschni, 1967).

The connective heat transfer model proposed by Woschni is defined as:

$$
h=\frac{A \cdot p^{0.8}}{T^{0.55} D_{c y l}^{0.2}}\left(B \cdot \bar{U}_{p i s t o n}+C \cdot \bar{U}_{\text {swirl }}+D \cdot \frac{T_{s o c} \cdot V \cdot\left(p-p_{\text {motor }}\right)}{p_{s o c} \cdot V_{s o c}}\right)^{0.8}
$$

Where

$\mathrm{h}=$ heat transfer coefficient $\left[\mathrm{W} / \mathrm{m}^{2} \mathrm{~K}\right], \mathrm{A}, \mathrm{B}, \mathrm{C}, \mathrm{D}=$ Woschni coefficients, $\mathrm{P}, \mathrm{T}, \mathrm{V}=$ cylinder pressure, cylinder temperature, cylinder volume respectively, $\bar{U}_{\text {piston }}=$ mean piston speed, $\bar{U}_{\text {swirl }}=$ mean swirl velocity, $T_{s o c}, p_{s o c}, V_{s o c}=$ cylinder gas temperature, pressure, volume at start of combustion, $p_{\text {motor }}=$ motoring cylinder pressure

The motoring cylinder pressure is given by:

$$
p_{\text {motoring }}=p_{\text {soc }}\left(\frac{V_{\text {soc }}}{V_{c y l}}\right)^{G}
$$

Where

$\mathrm{G}=$ Woschni ratio of specific heat

Thus the heat transfer per unit area of cylinder wall is defined as:

$$
\frac{d Q}{F}=h\left(T_{\text {gas }}-T_{\text {wall }}\right)
$$

The engine geometry data are shown in Table (1). The test is carried out for methane as a mean fuel. The engine speed is varying between $1000-$ $6000 \mathrm{rpm}$. The brake power, brake torque, brake thermal efficiency, and fuel consumption were calculated and analyzed. The fuel properties are illustrated in the table (2). The spark initiation $16^{\circ}$ bTDC and kept constant for all tests. The equivalence ratio $\phi=1$ for all simulations. 
Table (1) engine geometry

\begin{tabular}{ll}
\hline Bore & $87 \mathrm{~mm}$ \\
Stroke & $84 \mathrm{~mm}$ \\
Connecting rod length & $130 \mathrm{~mm}$ \\
Compression ratio & 11 \\
Max. intake valve lift & $8.5 \mathrm{~mm}$ \\
Max. exhaust valve lift & $8 \mathrm{~mm}$ \\
IVO angle & $17^{\circ} \mathrm{bTDC}$ \\
IVC & $62^{\circ}$ aBDC \\
EVO & $37^{\circ} \mathrm{bBDC}$ \\
EVC & $21^{\circ} \mathrm{aTDC}$ \\
\hline
\end{tabular}

\section{Results and discussion}

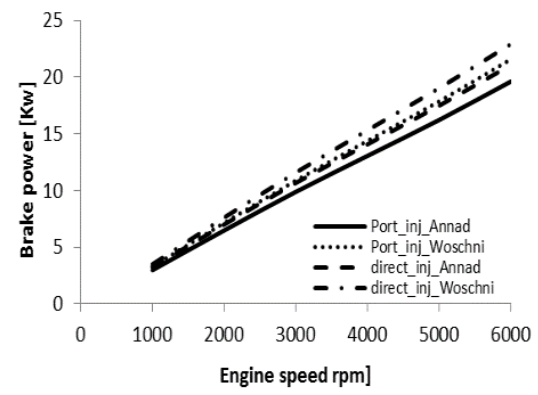

Fig. 1 Brake power for different fuel systems, heat transfer models and engine speed for methane

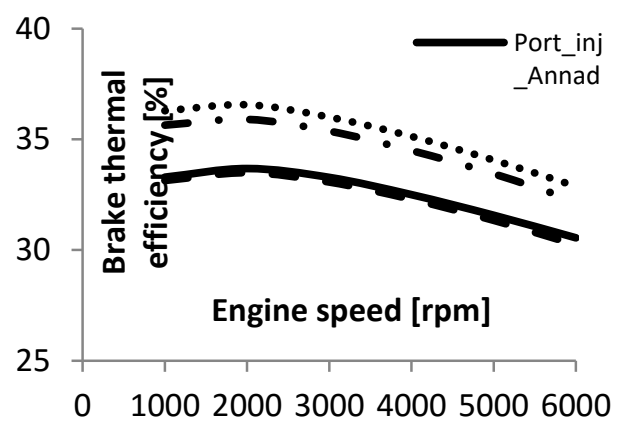

Fig. 3 Brake thermal efficiency for different engine speed fuel systems, and heat transfer models
Table (2) fuel properties

\begin{tabular}{ll}
\hline parameter & methane \\
\hline Relative density [kg/litr] & 0.00074 \\
Calorific value [kJ/kg] & 46280 \\
Molecular mass [kg/kmol] & 17.423 \\
H/C ratio & 3.87 \\
O/C ratio & 0 \\
\hline
\end{tabular}

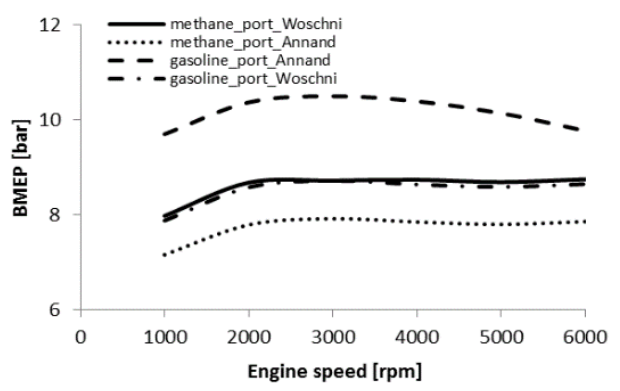

Fig. 2 Brake mean effective pressure for different fuel systems, heat transfer models, and engine speed

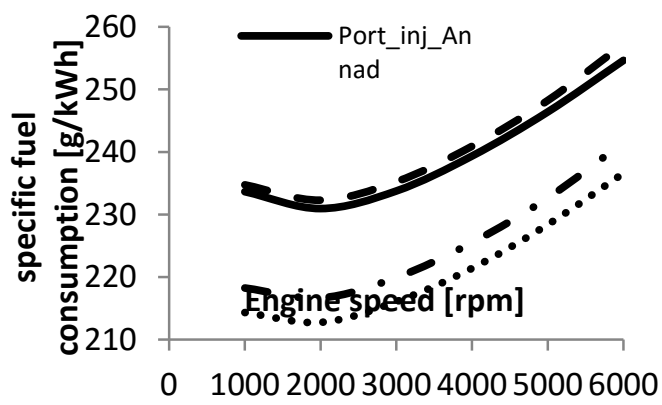

Fig. 4 Fuel consumption for different fuel systems, and heat transfer models

For the running conditions shown above, the simulation has been made for different fuel systems and heat transfer models. Figure (1) presents the brake power versus engine speed for different fuel systems and heat transfer models for methane. It shows that methane has the maximum brake 
power with Woschni model comparing with the Annand model which is in agreement with (Demuynck, 2011). This is because of Annand coefficients variations which should be calibrated for each engine run and the lack of some important parameters to precisely describe the heat transfer process in the engine. Moreover, the direct fuel system has higher power than port injection system for both heat transfer models. This is associated with turbulence intensity which gets higher value of the in-cylinder pressure and maximum rate of pressure rises, shorter combustion duration, and consequently increased combustion process efficiency (Ghazal, 2013).

Figure (2) shows the variation of brake mean effective pressure for Annad and Woschni models with different fuel systems and different engine speed. It shows a good agreement between Woschni model for methane fuel and gasoline fuel which is expected. The Annad model underestimated the mean pressure inside the engine which influence on the heat transfer rate.

Figure (3) shows the change of brake thermal efficiency versus engine speed for different fuel systems. It shows that the Woschni port injection model has the highest thermal efficiency than the direct systems. In addition, the Woschni model has higher thermal efficiency than the Annand model for all engine speed. This is due to the higher losses from the walls and cylinder head area and the higher heat transfer rate for Annand model (Borman, 1967).

Figure (4) shows the variation of BSFC versus engine speed, heat models and fuel systems, this show that BSFC is increased for Annand model comparing with Woschni model. The minimum fuel consumption is presented by port injection Woschni model. The lowest BSFC can be found where the thermal efficiency is highest and the brake power produced is proportionally high (Yusuf, 1990).

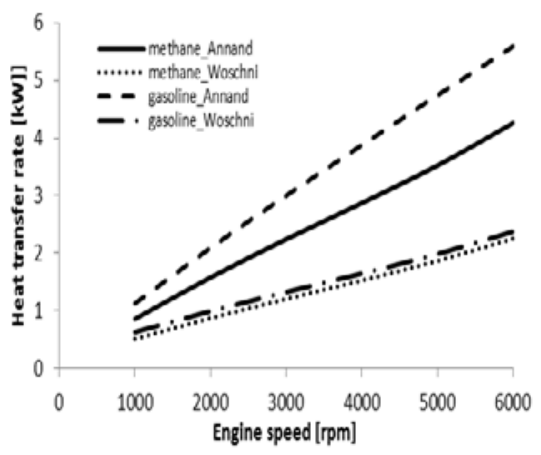

Fig. 5 Heat transfer for different engine speed, speed, fuel, fuel, and heat transfer models

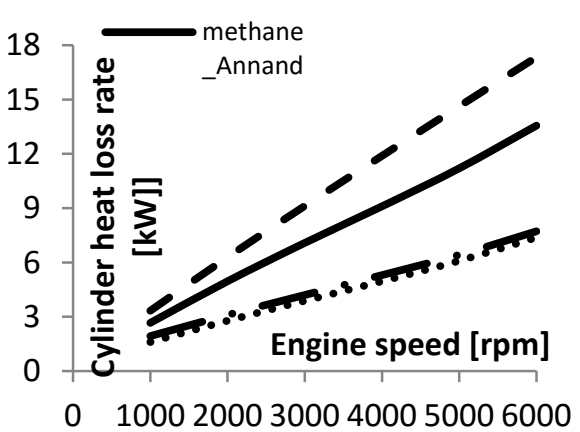

Fig. 6 heat loss rate for different engine and heat transfer models 
Figure (5) shows the heat transfer rate for both models. It presents a good agreement between the heat transfer rate for gasoline and methane using Woschni model compared with Annand model which shows a different heat transfer rate for both fuel. This is also presented by figure (6) which illustrates the heat loss rate for both models and both fuels. Hence, the Woschni model is a good choice for methane combustion process and heat transfer simulation.

\section{Conclusion}

The results show that the use of Woschni heat transfer model for the SI engine with methane fuel is recommended for all engine speed because it has high brake power, high thermal efficiency and lower fuel consumption. It has a good agreement with heat transfer model for gasoline fuel.

\section{Acknowledgment}

The author is grateful to the applied Science Private University, Amman, Jordan, for the full financial support granted to this research (Grant No. DGRS-2014-2015-132)

\section{References:}

Nusselt, W.: Der Warmeubergang in der Verbrenungskraftmaschene, Z. Verdt. Lng. 67(1923):692-708

Chirkov, A. and Stefanovski, B. S. 0 dominiruyushchem sposobye pyeryedachi tepla $\mathrm{v}$ tsilindrach dvigatyelyei vnutryennyevo sgoraniya, Trudy rosror. Inst. Injy. Fyelyenodorot'nora Transp. 21 (1958).

Van Tyens. W.: Methode zur Berechung der Zylinderbuchsentemperaturen in Dieselmotoren. Disseratation Thesis. U. Delft. Netherlands (1962)

Pflaum, W. Warmeubergang bei Dieselmaschienen mit und ohne Auffiadung, MTZ 22, 3 (1961).

Annand, W. Heat Transfer in the Cylinder of Reciprocating Internal Combustion Engines”, Proceeding Institution of Mechanical Engineers 1963; 177 (36):973-96.

Woschni G. A universally applicable equation for the instantaneous heat transfer coefficient in the internal engine. SAE paper 670931; 1967

Borman, G. Nishiwaki, K.: Internal-combustion engine heat transfer. Progress in Energy and combustion Science, 13 (1987): 1-46

Karim, G. Wierzba, I and AL-Alousi, Y,” Methane-Hydrogen Mixtures as fuels”, Int. J. Hydrogen Energy Vol. 21, No. 7, pp. 625- 631. 1996.

Hoehn FW, Baisly RL, Dowdy MW. Advances in ultralean combustion technology using hydrogen- enriched gasoline, Proceedings of the $10^{\text {th }}$ 
Intersociety Energy Conversion Conference, Newark, DE, USA, Paper 759173, 1975

Sher E, Hacohen Y. Measurements and predictions of the fuel consumption and emission of a spark ignition engine fueled with hydrogen-enriched gasoline. J Power Energy 1989; 203:155-62

Hacohen Y, Sher E. Fuel consumption and emission of SI engine fueled with $\mathrm{H}_{2}$-enriched gasoline. Proceedings of the 24th IECEC, Arlington, VA, USA, 1989, p. 2485-90.

Ghazal O. A comparative evaluation of the performance of different fuel induction techniques for blends hydrogen - methane SI engine. Int. J. Hydrogen Energy 38 (2013), pp. 6848-6856.

Raman V, Hansel J, Fulton J, Lynch F, Bruderly D. Hythane - an ultraclean transportation fuel. Hydrogen Fuel for Surface Transportation, SAE Publication, 1996, p. 47-56.

Nagalingam B, Duebel F, Schmillen K. Performance study using natural gas, hydrogen supplemented natural gas and hydrogen in AVL research engine. Int. J Hydrogen Energy 1983; 8(9):715-20.

Das LM. "Utilization of hydrogen-CNG blends in internal combustion engine”, $11^{\text {th }}$ World Hydrogen Energy Conference, Stuttgart, Germany, June 23-28, 1996, p. 1513-35

Annand, G. Balamurugan, R.: Optimization of Design and Operational Parameters Using Genetic Algorithm for a Spark Ignition Engine With CNG/H2 Mixtures, Paper No. IMECE2005-82145, pp. 259-265; 7, doi: 10.1115/IMECE2005-82145

Demuynck, J. De Paepe, M. Huisseune, H. Sierens, R. Vancoillie, J. Verhelst, S.: On the applicability of empirical heat transfer models for hydrogen combustion engines. International journal of hydrogen energy 36 (2011): 975-984

Lounici, M., Loubar, K., Balistrou, M. Tazerout, M.: Investigation on heat transfer evaluation for a more efficient two-zone combustion model in the case of natural gas SI engines. Applied Thermal Engineering 31 (2011): 319328

Szwaja, S., Rogalinski, K.: Hydrogen combustion in a compression ignition diesel engine. Int. J. Hydrogen Energy 34 (2009), pp. 4413-4421

Ferguson, R. and Kirkpatrick. A, Internal combustion engines applied thermodynamics”, $2^{\text {nd }}$ Edition, John Wiley and sons inc., New York, 2001.

Baur, H., "Gasoline-engine Management - Basic components"; Bosch Company, 1st edition, Stuttgart, 2001.

Stone, "Introduction to Internal Combustion Engines"; McMillan Press, 3rd edition, London, 1999. 
Yusuf MJ. "In cylinder flame front growth rate measurement of methane and hydrogen enriched methane fuel in a spark ignited internal combustion engine”. Master thesis, University of Miami, 1990

Ghazal, O.: A theoretical study of the SI engine performance operating with different fuels. International journal of mechanical, aerospace, industrial and mechatronics engineering 7 (12), 2013 